\title{
EJCP Decision
}

RE: EJCP062515R1, entitled "Surviving a childhood cancer: impact on education and employment"

Dear Dr Maule,

I am pleased to inform you that your work has now been accepted for publication in European Journal of Cancer Prevention. All manuscript materials will be forwarded immediately to the production staff for placement in an upcoming issue.

\section{OPEN ACCESS}

If you indicated in the revision stage that you would like your submission, if accepted, to be made open access, please go directly to step 2. If you have not yet indicated that you would like your accepted article to be open access, please follow the steps below to complete the process:

1. Notify the journal office via email that you would like this article to be available open access. Please send your Email to Janssens.ecp@skynet.be. Please include your article title and manuscript number.

2. A License to Publish (LTP) form must be completed for your submission to be made available open access. Please download the form from

http://links.Iww.com/LWW-ES/A49, sign it, and Email the completed form to the journal office.

3. Within 48 hours of receiving this e-mail: Go to http://wolterskluwer.qconnect.com to pay for open access. You will be asked for the following information. Please enter exactly as shown:

a. Article Title - Surviving a childhood cancer: impact on education and employment

b. Manuscript Number - EJCP062515R1

Thank you for submitting your interesting and important work to the journal.

http://ejcp.edmgr.com/

With Kind Regards,

Jaak Ph. Janssens, MD, PhD

Editor

European Journal of Cancer Prevention 